\title{
Produção de biofilme por Staphylococcus chromogenes isolados de amostras de leite provenientes de rebanhos bovinos com mastite
}

\author{
[Biofilme production by Staphylococcus chromogenes isolated from milk samples from \\ bovine with mastitis] \\ L.F.S. Israel ${ }^{1}$, R.F. Rabello ${ }^{2}$, S.C.B. Domingos ${ }^{1}$, L.S. Medeiros ${ }^{1}$ \\ ${ }^{1}$ Universidade Federal do Acre - Rio Branco, AC \\ ${ }^{2}$ Universidade Federal Fluminense - Niterói, RJ
}

\section{RESUMO}

Foram estudadas 135 vacas mestiças, provenientes de 10 rebanhos leiteiros no estado do Acre. O objetivo foi identificar espécies de Staphylococcus isoladas dos quartos mamários de vacas com mastite e, posteriormente, avaliar a capacidade de produção de biofilme pela espécie Staphylococcus chromogenes. A caracterização dos isolados presentes nas amostras encontradas, correspondentes a Staphylococcus sp., foi realizada utilizando-se a técnica do MALDI TOF MS (Matrix Associated Laser Desorption-Ionization - Time of Flight - Mass Spectrometry). Foram identificados: S. chromogenes (36), Staphylococcus saprophyticus (5), S. chromogenes ou Staphylococcus hycus (5), Staphylococcus haemolyticus (4), Staphylococcus epidermidis (3), Staphylococcus hycus (3), Staphylococcus aureus (1), Staphylococcus auriculares (1), Staphylococcus kloosii (1) e Staphylococcus xylosus (1). A espécie S. chromogenes correspondeu a $60 \%$ dos isolados do gênero (17 isolados coagularam o plasma de coelho no teste da coagulase em tubo), sendo 83,3\% dos isolados (30/36) produtores de biofilme, não estando esse fator de virulência associado ao fenótipo de coagulação do plasma. A identificação desses microrganismos é importante para a elucidação da etiologia da mastite bovina. O alto percentual de S. chromogenes, produtores de biofilme, isolados de vacas com mastite é um achado relevante e pode revelar uma mudança de perfil na colonização de agentes etiológicos causadores dessa enfermidade.

Palavras-chave: Staphylococcus sp., MALDI TOF MS, virulência, mastite bovina

\begin{abstract}
A total of 135 crossbred cows was studied, from ten dairy herds on the state of Acre. The purpose was to identify species of Staphylococcus isolated from the mammary quarters of cows with mastitis. Additionally, the capacity of biofilm production by the species Staphylococcus chromogenes was evaluated. The sample characterization of the isolates was performed using the MALDI TOF MS (Matrix Associated Laser Desorption-Ionization - Time of Flight - Mass Spectrometry). The following species were identified by MALDI TOFF MS: S. chromogenes (36), Staphylococcus saprophyticus (5), S. chromogenes or Staphylococcus hycus (5), Staphylococcus haemolyticus (4), Staphylococcus epidermidis (3), Staphylococcus hycus (3), Staphylococcus aureus (1), Staphylococcus auriculares (1), Staphylococcus kloosii (1) and Staphylococcus xylosus (1). S. chromogenes corresponded to $60 \%$ of the Staphylococcus isolates (17 isolates positive on tube coagulase test). From those, $83.33 \%$ (30/36) of them were biofilm producers. This virulence factor had no association with the plasma coagulation phenotype. The identification of these microorganisms is important for the elucidation of the bovine mastitis etiology. The high percentage of $\mathrm{S}$. chromogenes, biofilm producers, isolated from cows with mastitis is an important finding. This may reveal a profile change on the colonization of etiologic agents that cause this disease.
\end{abstract}

Keywords: Staphylococcus sp., MALDI TOF MS, virulence, bovine mastitis

Recebido em 24 de julho de 2017

Aceito em 1 de fevereiro de 2018

E-mail: larissafreitas.vet@gmail.com 


\section{INTRODUÇÃO}

A mastite bovina é considerada a principal doença que afeta os rebanhos leiteiros em todo o mundo, causando sérios prejuízos econômicos na produção bovina leiteira mundial (Freitas et al., 2005; Hoogeveen et al., 2011).

Entre os patógenos mais prevalentes associados com mastite em vacas em lactação estão as bactérias pertencentes ao gênero Staphylococcus sp., sendo divididos em Staphylococcus coagulase negativa (SCN) e Staphylococcus coagulase positiva (SCP) (Pyörälä e Taponen, 2009; De Vliegher et al., 2012). Apesar de serem considerados menos patogênicos que os Staphylococcus aureus, as infecções causadas por SCN têm sido associadas com perdas consideráveis de leite e tendem a persistir durante todo o período da produção (Pÿorala e Taponen, 2009).

Staphylococcus chromogenes é uma espécie de SCN não hemolítica. Foi originalmente considerada uma subespécie de Staphylococcus hyicus, no entanto, atualmente, é classificada como uma espécie separada (Hajek et al., 1986). $S$. chromogenes tem sido encontrado como espécie mais prevalente de $\mathrm{SCN}$ associado à mastite em gado leiteiro em vários estudos (Tomazi et al., 2014; Srednik et al., 2015). Adicionalmente, esta espécie está associada a infecções persistentes e com alta contagem de células somáticas (Supré et al., 2011).

Atualmente se discute o papel dos fatores de virulência do gênero Staphylococcus sp., como a coagulase e a produção de biofilme, na persistência e disseminação no hospedeiro, na expressão da doença grave e na interferência do tratamento com antimicrobianos (Pyörälä e Taponen, 2009; Giardini, 2013; Marques et al., 2013). Biofilmes são descritos como aglomerações de células embebidas em matriz heterogênea extracelular, que resultam em estruturas tridimensionais com características fisiológicas específicas e dificultam a ação dos macrófagos, além de aumentarem a resistência a diversos antimicrobianos (Marques et al., 2013).

O presente trabalho teve como objetivo identificar a ocorrência de isolados do gênero Staphylococcus nos quartos mamários de vacas com mastite provenientes de rebanhos bovinos do estado do Acre, bem como avaliar a capacidade de produção de biofilme pela espécie S. chromogenes

\section{MATERIAL E MÉTODOS}

O experimento foi realizado após aprovação do Comitê de Ética no Uso de Animais em Ensino e Pesquisa (Ceua) da Universidade Federal do Acre (UFAC), conforme o parecer 61/2015.

Foram selecionadas 10 propriedades leiteiras, localizadas nos municípios de Rio Branco e Senador Guiomard - AC, com histórico de queda de produção e com, no máximo, 35 vacas em lactação, durante o período de novembro de 2015 a agosto de 2016. Três das 10 propriedades selecionadas utilizam ordenha mecânica e as sete restantes, ordenha manual. $\mathrm{Na}$ maioria das propriedades, não eram aplicadas várias práticas de controle, como higienização e imersão dos tetos em antissépticos antes e após a ordenha, uso do California Mastitis Test (CMT) para identificação da mastite subclínica e tratamento da mastite clínica com produtos prescritos por veterinários.

Inicialmente, foi realizado exame clínico da glândula mamária. Em seguida, realizou-se a lavagem dos tetos com água e sabão, secagem com papel-toalha e antissepsia do óstio com álcool 70\%. Os três primeiros jatos de leite foram desprezados em caneca telada e, em seguida, foi realizado o CMT para cada teto, a fim de ser realizada a identificação de animais com mastite subclínica (Fonseca e Santos, 2000).

O critério de classificação da mastite clínica foi a detecção de alterações da glândula mamária compatíveis com processo inflamatório ao exame clínico e/ou a presença de alterações macroscópicas no leite, tais como presença de grumos e coloração alterada (Fonseca e Santos, 2000).

Uma vez diagnosticada a mastite, clínica ou subclínica, foram coletados aproximadamente $5 \mathrm{~mL}$ de leite do teto acometido, em tubos do tipo Falcon previamente esterilizados. O material foi acondicionado a $\quad 4^{\circ} \mathrm{C}$ e encaminhado imediatamente ao laboratório para análises microbiológicas. 
As amostras de leite foram semeadas em ágar sangue contendo $5 \%$ de sangue ovino (Laboclin), incubadas em condições aeróbias a $37^{\circ} \mathrm{C}$, por 24 até 48 horas (Machado et al., 2008). As colônias suspeitas foram semeadas posteriormente em ágar Mueller Hinton (Kasvi), também incubadas em condições aeróbias a $37^{\circ} \mathrm{C}$, por 24 até 48 horas. A identificação inicial dos isolados foi realizada por morfologia colonial, coloração de Gram, teste da catalase e teste da coagulase em tubo (Microbiological..., 2004).

Após a identificação inicial, as amostras sugestivas do gênero Staphylococcus foram submetidas à técnica de MALDI TOF no equipamento MALDI Biotypes 3.1 (Bruker Daltonik, Bremen, Germany).

A caracterização da produção de biofilme foi avaliada quantitativamente pelo teste de aderência em microplaca, com modificações na metodologia proposta por Christensen et al. (1985) e Cucarella et al. (2001). As bactérias foram inoculadas na concentração de $1 \mathrm{UFC} / \mathrm{mL}$, em meio Tryptic Soy Both (TSB) (Kasvi), e incubadas a $37^{\circ} \mathrm{C}$ por $24 \mathrm{~h}$. Posteriormente, as células em suspensão foram inoculadas em microplacas de poliestireno estéreis com 96 poços, diluídas em 1:40 em TSB e incubadas por 24 horas a $37^{\circ} \mathrm{C}$ sem agitação.

Após incubação, os poços foram lavados duas vezes com $200 \mu \mathrm{L}$ de solução salina estéril, secos em estufa a $60^{\circ} \mathrm{C}$ e deixados até a secagem da placa, durante 30 minutos. Adicionaram-se, então, $200 \mu \mathrm{L}$ de cristal violeta a $1 \%$ por 15 minutos. Em seguida, os poços foram lavados três vezes com água destilada e secos em temperatura ambiente. A absorbância foi determinada a 490nm em leitor de ELISA (Polaris, Celer). Poços não inoculados contendo apenas TSB serviram como controle negativo. As leituras foram realizadas em triplicata e os valores da densidade óptica (DO), tomados como a média das leituras.

As amostras foram classificadas em quatro categorias, de acordo com a média das DOs relacionada com os resultados obtidos para o controle negativo (DOCN) (Peña e Uffo, 2013). As categorias foram baseadas nos seguintes critérios: não aderente (NA), quando a DO $\leq$ DOCN; fracamente aderente (+), quando a DOCN $<$ DO $\leq 2 \mathrm{x}$ DOCN; moderadamente aderente $(++)$, quando $2 \mathrm{x}$ DOCN $<\mathrm{DO} \leq 4 \mathrm{x}$ DOCN; ou fortemente aderente $(+++)$, quando 4x DOCN <DO.

\section{RESULTADOS E DISCUSSÃO}

Foram avaliados os quartos mamários de 135 vacas mestiças, provenientes de 10 propriedades leiteiras localizadas no estado do Acre. Sessenta e sete (67) vacas foram classificadas como tendo mastite $(49,63 \%)$. Destas, três foram identificadas com mastite clínica $(4,5 \%)$ e 64 com mastite subclínica $(95,5 \%)$.

Foram coletadas amostras de leite de 162 tetos provenientes de 67 vacas com mastite. Foram isoladas colônias suspeitas indicativas do gênero Staphylococcus de 83 tetos, correspondentes a 55 vacas. Os isolados suspeitos foram submetidos ao MALDI TOF. Foi confirmada a presença de 60 isolados do gênero Staphylococcus em 57 tetos de 40 vacas. Entre os 60 isoladas de Staphylococcus sp., foram identificados: $S$. chromogenes (36), Staphylococcus saprophyticus (5), Staphylococcus haemolyticus (4), Staphylococcus epidermidis (3), S. hycus (3), S. aureus (1), Staphylococcus auriculares (1), Staphylococcus kloosii (1) e Staphylococcus xylosus (1). Cinco isolados não foram identificados quanto à espécie de forma confiável. A espécie $S$. chromogenes correspondeu a $60 \%(36 / 60)$ do total de isolados do gênero (Tab. 1).

No presente trabalho, foi encontrado somente um isolado da espécie $S$. aureus, resultado inesperado para este estudo, já que trabalhos na literatura (Rabello, 2007; Marques et al., 2013) a citam como a espécie mais frequentemente isolada em casos de mastite. 
Israel et al.

Tabela 1. Distribuição das espécies de Staphylococcus isoladas de vacas com mastite entre as diferentes propriedades investigadas no Acre

\begin{tabular}{|c|c|c|c|}
\hline Espécie (n) & Propriedade & Vaca (n) & Teto $(\mathrm{n})$ \\
\hline \multirow{9}{*}{ S. chromogenes $(36)^{\mathrm{a}}$} & $\mathrm{A}$ & 1 & 1 \\
\hline & $\mathrm{B}$ & 1 & 1 \\
\hline & $\mathrm{C}$ & 2 & 2 \\
\hline & $\mathrm{E}$ & $3(1 *)$ & $5\left(3^{*}\right)$ \\
\hline & $\mathrm{F}$ & 4 & 7 \\
\hline & $\mathrm{G}$ & 2 & 3 \\
\hline & $\mathrm{H}$ & 3 & 3 \\
\hline & I & 2 & 2 \\
\hline & $\mathrm{J}$ & 8 & 10 \\
\hline \multirow{3}{*}{ S. saprophyticus (5) } & $\mathrm{C}$ & 1 & 1 \\
\hline & $\mathrm{E}$ & 1 & 1 \\
\hline & $\mathrm{F}$ & 2 & 3 \\
\hline S. haemolyticus (4) & I & 4 & 4 \\
\hline \multirow{2}{*}{ S. epidermidis (3) } & $\mathrm{C}$ & 1 & 1 \\
\hline & $\mathrm{J}$ & 2 & 2 \\
\hline S. hycus (3) & $\mathrm{H}$ & 2 & 3 \\
\hline S. aureus (1) & A & 1 & 1 \\
\hline S. auriculares (1) & I & 1 & 1 \\
\hline S. kloosii (1) & $\mathrm{H}$ & 1 & 1 \\
\hline S. xylosus (1) & $\mathrm{H}$ & 1 & 1 \\
\hline
\end{tabular}

${ }^{a}$ Uma única colônia foi selecionada de cada teto para o estudo, com exceção de dois tetos, de onde foram isoladas duas colônias com fenótipos diferentes.

*Fora dos parênteses, é o número de vacas ou de tetos com infecção; enquanto dentro dos parênteses, é o número daqueles(as) com infecção clínica.

O isolamento de S. chromogenes neste estudo está de acordo com resultados encontrados na literatura (Sampimon et al., 2009; Piessens et al., 2011; Supré et al., 2011; Fry et al., 2014; Srednik et al., 2015), que têm mostrado a disseminação desse agente em rebanhos bovinos, inclusive no Brasil (Santos et al., 2008; Lange et al., 2011; Tomazi et al., 2014), sendo $S$. chromogenes atualmente a espécie de SCN mais frequentemente isolada de mastite bovina. No entanto, Bochniarz et al. (2014) encontraram uma frequência maior de $S$. xylosus entre todos os SCN isolados de vacas com mastite clínica e subclínica, seguido por S. chromogenes, sendo essa a espécie mais prevalente quando considerada apenas a forma subclínica da mastite.

Entre os isolados de S. chromogenes, 47,2\% (17/36) apresentaram a capacidade de coagular o plasma no teste da coagulase em tubo, apesar de esta espécie ser considerada SCN. Dois desses isolados foram recuperados de tetos onde também foram recuperados isolados que se apresentaram negativos no teste da coagulase em tubo. O fenótipo coagulase positiva de isolados de $S$. chromogenes foi relatado anteriormente em outros estudos (Lange et al., 2011; d Santos et al., 2016). Lange et al. (2011) isolaram 53,9\% (7/13) dos isolados de $S$. chromogenes provenientes de mastite bovina que se apresentaram positivos no teste da coagulase em tubo. A atividade de coagulação desses isolados pode ser causada por interferência de proteases, porém estudos devem ser realizados para explicar melhor. A capacidade de coagular plasma pode levar à identificação equivocada dessa espécie em outras mais prevalentes, como S. aureus.

S. chromogenes é filogeneticamente mais semelhante a muitos SCP e coagulase variáveis (Santos et al., 2016). Na sequência genômica de $S$. chromogenes, há uma open reading frame com $41 \%$ de identidade com o gene da coagulase da espécie de SCP Staphylococcus pseudintermedius (Fry et al., 2014). Essa descoberta reforça a necessidade de metodologias que possam diferenciar essas espécies. A identificação por MALDI TOF de várias espécies de Staphylococcus é confiável. No estudo realizado por Tomazi et al. (2014), 
$100 \%$ dos isolados de S. chromogenes foram identificados por tal técnica.

Um grande progresso para o diagnóstico em microbiologia é o método hoje conhecido como MALDI-TOF MS (Matrix Associated Laser Desorption-Ionization - Time of Flight - Mass Spectrometry), tornando-se atualmente um recurso de referência para microbiologistas que trabalham nos laboratórios de rotina, devido a sua característica de permitir a identificação confiável e rápida de microrganismos (Benagli et al., 2011; Zárate et al., 2014).

Trinta $(83,3 \%)$ isolados de $S$. chromogenes foram identificados como produtores de biofilme. Dos isolados com capacidade para coagular o plasma, 70,6\% (12/17) são produtores de biofilme e $29,4 \%$ (5/17) não são produtores. Já entre os isolados de $S$. chromogenes que não coagularam o plasma, $94,7 \% \quad(18 / 19)$ são produtores de biofilme e apenas 5,3\% (1/19) não foram produtores (Fig. 1).

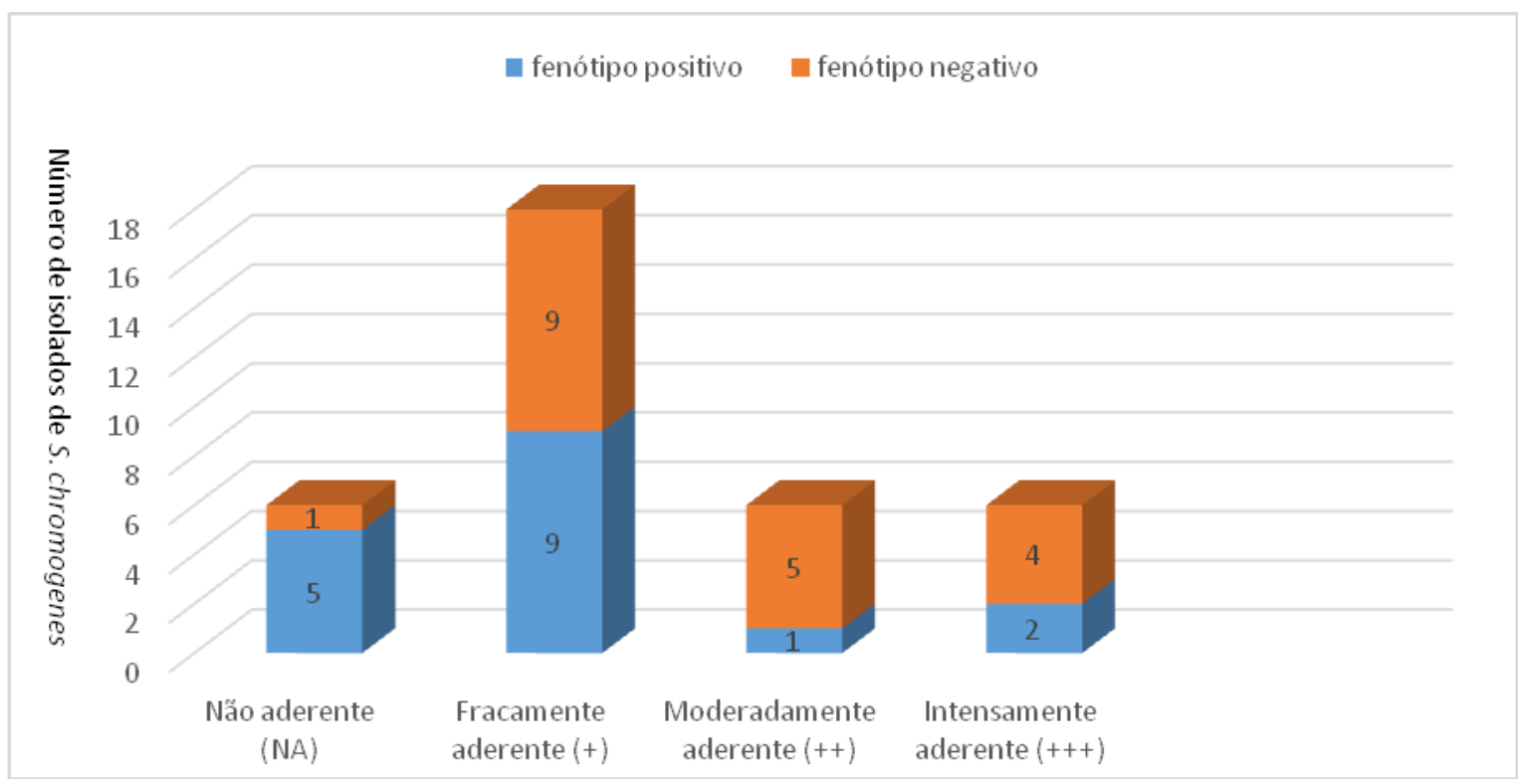

Figura 1. Classificação da produção de biofilme por S. chromogenes.

Fry et al. (2014) identificaram dois genes de proteínas associadas à produção de biofilme em $S$. chromogenes, por meio de seu sequenciamento genômico. Bochniarz et al. (2014) avaliaram a produção de slime por SCN isolados de vacas com mastite e encontraram $38,5 \%$ (10/26) dos isolados de S. chromogenes com essa capacidade. Em estudo realizado por Bochniarz et al. (2016), a capacidade de produzir slime foi confirmada em 24 isolados $(63,2 \%)$ de S. chromogenes.

Há um consenso de que o biofilme contribua para a persistência bacteriana em sítios infecciosos ou para infecções crônicas, pois dificulta a ação dos mecanismos de defesa do hospedeiro e de agentes antimicrobianos. Além disso, as cepas de Staphylococcus produtoras desse polissacarídio extracelular têm maior capacidade para colonizar (Cucarella et al., 2001; Giardini, 2013).

O alto percentual de Staphylococcus chromogenes, produtores de biofilme, isolados de vacas com mastite é um achado importante deste estudo e pode revelar uma mudança de perfil na colonização de agentes etiológicos causadores dessa enfermidade. Esse achado pode ser decorrente também do uso de novas técnicas diagnósticas, como o MALDI TOF MS. Atualmente, os métodos de identificação dos estafilococos estão sendo reavaliados e, com isso, estão sendo desenvolvidos métodos moleculares, podendo ser esperados avanços substanciais no conhecimento sobre a mastite bovina causada por Staphylococcus. 
Foram observados isolados de S. chromogenes, denotados como coagulase negativos em literatura, entretanto com capacidade de coagular o plasma. Estudos adicionais são necessários para elucidar os mecanismos que conferem a capacidade de coagular o plasma nesses isolados de $S$. chromogenes e o papel desse fenótipo na virulência dessa espécie. Além disso, a fenotipagem pode facilmente levar a erros de identificação de $S$. aureus, espécie pouco prevalente no presente estudo e citada como a espécie SCP mais prevalente em mastite. Resta avaliar se o $S$. chromogenes coagulase negativo deve ser reclassificado como um coagulase variável.

\section{CONCLUSÕES}

Foi confirmada a presença de 60 isolados pertencentes ao gênero Staphylococcus isolados de 57 tetos provenientes de 40 vacas com mastite. A espécie $S$. chromogenes correspondeu a $60 \%(36 / 60)$ do total de isolados do gênero, demonstrando a importância dessa espécie como agente causador da mastite em bovinos. Trinta $(83,3 \%)$ isolados de $S$. chromogenes foram identificados como produtores de biofilme. Dos isolados de $S$. chromogenes com capacidade para coagular o plasma, 70,6\% (12/17) são produtores de biofilme. Já entre os isolados de $S$. chromogenes que não coagularam o plasma, 94,7\% (18/19) são produtores de biofilme. Esses dados mostram um alto percentual desse fator de virulência nas cepas isoladas.

\section{REFERÊNCIAS}

BENAGLI, C.; ROSSI, V.; DOLINA, M. et al. Matrix-assisted laser desorption ionization-time of flight mass spectrometry for the identification of clinically relevant bacteria. PLoS One, v.6, p.e16424, 2011.

BOCHNIARZ, M.; ADASZEX, L.; DZIEGIEL, B. et al. Factors responsible for subclinical mastitis in cows caused by Staphylococcus chromogenes and its susceptibility to antibiotics based on bap, fnbA, eno, mecA, tetK, and ermA genes. J. Dairy Sci., v.99, p.9514-9520, 2016.

BOCHNIARZ, M.; WAWRON, W.; SZCZUBIAL, M. Production of slime by coagulase-negative staphylococci (CNS) isolated from clinical and subclinical mastites in cows. Polish J. Vet. Sci., v.17, p.447-452, 2014.
BRITO, M.A.V.P.; BRITO, J.R.F. Diagnóstico microbiológico da mastite. Juiz de Fora, MG: Embrapa Gado de Leite, 1999. 26p. (Circular Técnica, 55).

CHRISTENSEN, G.D.; SIMPSON, W.A.; YOUNGER, J.J. et al. Adherence of coagulaseactive staphylococci to plastic tissue culture plates: a quantitative model for the adherence of staphylococci to medical devices. J. Clin. Microbiol., v.22, p.996-1006, 1985.

CUCARELLA, C.; SOLANO, C.; VALLE, J. et al. Bap, a Staphylococcus aureus Surface Protein Involved in Biofilm Formation. J. Bacteriol., v.183, p.2888-2896, 2001.

DE VLIEGHER, S.; FOX, L.K.; PIEPERS, S. et al. Invited review: Mastitis in dairy heifers: nature of the disease, potential impact, prevention, and control. J. Dairy Sci., v.95, p.1025-1040, 2012.

FONSECA, L.F.L.; SANTOS, M.V. Qualidade do leite e controle da mastite. São Paulo: Lemos, 2000. 314p.

FREITAS, M.F.L.; PINHEIRO JUNIOR, J.W.; STAMFORD, T.L.M. et al. Perfil de sensibilidade antimicrobiana in vitro de Staphylococcus coagulase positivos isolados de leite de vacas com mastite no agreste do Estado de Pernambuco. Arq. Inst. Biol., v.72, p.171-177, 2005.

FRY, P.R.; CALCUTT, M.J.; FOECKING, M.F. et al. Draft genome sequence of Staphylococcus chromogenes strain MU 970, isolated from a case of chronic bovine mastitis. Genome Announc., v.2, p.e00835, 2014.

GIARDINI, L.K. Identificação de grupos clonais, resistência aos antimicrobianos $e$ presença de genes associados à formação de biofilmes (icaA e IcaD) em Staphylococcus aureus isolados de propriedades produtoras de leite bovino. 2013. 92f. Tese (Doutorado em Ciências Veterinárias). Universidade Federal do Rio Grande do Sul, Porto Alegre, RS.

HAJEK, V.; DEVRIESE, L.A.; MORDARSKI, M. et al. Elevation of Staphylococcus hyicus subsp. Chromogenes (Devriese et al., 1978) to Species Status: Staphylococcus chromogenes (Devriese et al., 1978) comb. nov. System. Appl. Microbial. v.8, p.169-173, 1986. 
HOOGEVEEN, H.; HUIJPS, K.; LAM, T.J.G.M. Economic aspects of mastitis: new developments. N. Z. Vet. J., v.59, p.16-23, 2011.

LANGE, C.C.; BRITO, M.A.V.P.; BRITO, J.R.F. et al. Uso de PCR e sequenciamento do rDNA 16S para identificação de bactérias do gênero Staphylococcus isoladas de mastite bovina. Pesqui. Vet. Bras., v.31, p.36-40, 2011.

MACHADO, T.R.O.; CORREA, M.G.; MARIN, J.M. Antimicrobial susceptibility of coagulasenegative Staphylococci isolated from mastitic cattle in Brazil. Arq. Bras. Med. Vet. Zootec., v.60, p.278-282, 2008.

MARQUES, V.F.; SOUZA, M.M.S.; MENDONÇA, E.C.L. et al. Análise fenotípica e genotípica da virulência de Staphylococcus spp. e de sua dispersão clonal como contribuição ao estudo da mastite bovina. Pesqui. Vet. Bras., v.33, p.161-170, 2013.

MICROBIOLOGICAL procedures for the diagnosis of bovine udder infection and determination of milk quality. 4.ed. Madison: National Mastitis Council, 2004.

PEÑA，J.; UFFO，O. Biofilm production of Staphylococcus aureus genotypes isolated from bovine mastitis in Cuba. Rev. Salud Anim., v.35, p.189-196, 2013.

PIESSENS, V.; VAN COILLIE, E.; VERBIST, B. et al. Distribution of coagulase-negative Staphylococcus species from milk and environment of dairy cows differs between herds. J. Dairy Sci., v.94, p.2933-2944, 2011.

PYÖRÄLÄ， S.; TAPONEN， S. Coagulasenegative staphylococci-emerging mastitis pathogens. Vet. Microbiol., v.134, p.3-8, 2009.

RABELLO, R.F. Diversidade genética e genes de virulência de amostras de Staphylococcus aureus isoladas de mastite bovina no estado do Rio de Janeiro. 2007. 161f. Tese (Doutorado) Instituto de Microbiologia Prof. Paulo de Góes/
Programa de Pós-Graduação em Microbiologia e Imunologia, Universidade Federal do Rio de Janeiro, Rio de Janeiro, RJ.

SAMPIMON, O.C.; BARKEMA, H.W.; BERENDS, I.M. et al. Prevalence and herd-level risk factors for intramammary infection with coagulase-negative staphylococci in Dutch dairy herds. Vet. Microbiol., v.134, p.37-44, 2009.

SANTOS, D.C.; LANGE, C.C.; AVELLARCOSTA, P. Staphylococcus chromogenes, a coagulase-negative Staphylococcus species that can clot plasma. J. Clin. Microbiol., v.54. p.1372-1375, 2016

SANTOS, O.C.S.; BARROS, E.M.; BRITO, M.A.V.P. et al. Identification of coagulasenegative staphylococci from bovine mastitis using RFLP-PCR of the groEL gene. Vet. Microbiol., v.130, p.134-140, 2008.

SREDNIK, M.E.; GRIEBEN, M.A.; BENTANCOR, A.; GENTILINI, E.R. Molecular identification of coagulase-negative staphylococci isolated from bovine mastitis and detection of $\beta$-lactam resistance. J. Infect. Dev. Ctries, v.9, p.1022-1027, 2015.

SUPRÉ, K.; HAESEBROUCK, F.; ZADOKS, R.N. et al. Some coagulase-negative Staphylococcus species affect udder health more than others. J. Dairy Sci., v.94, p.2329-2340, 2011.

TOMAZI, T.; GONÇALVES, J.L.; BARREIRO, J.R. et al. Identification of coagulase-negative staphylococci from bovine intramammary infection by matrix-assisted laser desorption ionization-time of flight mass spectrometry. $J$. Clin. Microbiol., v.52, p.1658-1663, 2014.

ZÁRATE, M.S.; ROMANO, V.; NIEVAS, J. et al. Utilidad de la espectrometria de masas MALDI-TOF en la identificación de bactérias anaeróbias. Rev. Argent. Microbiol., v.46, p.98102, 2014. 